\title{
DEVELOPMENT OF METHODOLOGY FOR IMPLEMENTATION OF STRATEGIC PLANNING - MISP
}

\author{
João Alberto Neves dos Santos \\ Instituto de Ciência e Tecnologia, UFF, Brazil \\ E-mail: joaoalbertoneves@gmail.com \\ Carlos Alberto Pereira Soares \\ Escola de Engenharia, UFF, Brazil \\ E-mail: carlos.uff@globo.com \\ João Thiago Machado dos Santos \\ Universidade do Estado do Rio de Janeiro, Brazil \\ E-mail: thiago.uerj@hotmail.com \\ Christian da Silva Dunga \\ Universidade do Estado do Rio de Janeiro, Brazil \\ E-mail: christiandunga@gmail.com
}

Submission: 11/04/2013

Revision: 17/04/2013

Accept: 27/08/2013

\section{ABSTRACT}

The development of this methodology was started in 1995, aimed at the implementation of strategic planning in an organization, using principles of strategy formulation school "Design School" at Harvard University. The methodology is presented structured steps that facilitate its implementation by an organization. Has already been tested in various public organizations, but is being proposal regarding any tpe of organization. To do this, you can make use of undergraduate students to assist in investigation methods and techniques can be applied in the various stages of the methodology, could then define the most appropriate methods and techniques in each step. Noteworthy that the methodology also provides for a performance measurement system that supports the actions of strategic planning.

Keywords: strategic planning, strategic management, organizational strategy. 


\section{INTRODUCTION}

The world goes through significant changes, some radicals, in the economic development model of countries in order to organize the society, in the way that the organizations are managed, and way of life of people.

After World War II, it came out of the task oriented organization model for the task itself, meaning, with the focus on the product and the production process, and went for the oriented organization to the client and to the market.

Today, more than ever, the internal and external environments of organizations are influenced by a high degree of turbulence (TRIST, 1976), so the need to increase the knowledge, particularly in countries like Brazil, less developed, that will face each time more the lack of information and relevant knowledge.

In fact, countries now need to participate in a globalized economy. Therefore, issues such as strategic planning, results management, information, management models, capacitation and pursuit of knowledge are a must, showing that a paradigm change occurs, that means changing the ideas, perspectives, and achievements, which are considered sufficient to explain a certain object under study and guide the managers' actions.

In Brazil, with the resumption of economic growth, it was found that the industrial sector remained at the forefront of this growth, reaching levels, in some segments, around 35\% in 2003-2005 (IEDI, 2007). Even in 2007 there was an industrial growth as a whole, around 6\% (FEIJÓ, CARVALHO, 2008).

In turn, The National Confederation of Commerce (Confederação Nacional do Comércio - CNC) has developed a study, an overview of the Brazilian Economy, presenting the results of Brazil's economy in 2007. It was cited in this study that "The 2007 numbers showed that the national GDP grew $5.4 \%$ meaning a significantly growth higher than the rate of $3.8 \%$ verified in $2006 \ldots$ Taken together, these figures speak for themselves: 2007 was a good year (GABEIRA, 2008, p.4)!"

On the other hand, at the end of 2008 the prosperous winds of economy changed. The international financial crisis reached the Brazilian companies, for "the loss of rhythm in the contractions proved to be generalized. In 12 of the 18 sectors 
surveyed, industrial employment was lower in January of 2009 compared to January 2008 (AMERICANO, 2009).

Surveys conducted by the Brazilian Institute of Geography and Statistics (Instituto Brasileiro de Geografia e Estatística - IBGE) in January of 2009 showed that "the production decreased by around $17 \%$ in January of 2009 , in comparison to the same month of 2008, the worst result in 19 years." (LIMA, 2009, p.4).

It is verified that, not only the market increase up to 2007 intensified the search for new clients, but also the loss of markets from the end of 2008. This only comes to confirm Liker's observations (2004), that clients are becoming each time more demanding about the characteristics of products and services, forcing the companies to strengthen their engineering and production areas, in order to obtain a production process and a product that are consistent, besides projecting their products in a faster way, more reliable and at a competitive cost..

This way, the organizations should make a proper diagnosis of the current situation of its action sector, so as not to be surprised by changes not only economic but also political, technological, social, legal, etc. that may interfere in its performance.

\section{RESEARCH METHODOLOGY}

Rigby and Bilodeau (2007), as shown on Figure 1, shows that the strategic planning is one of the main tools used by companies worldwide to direct the actions of companies and to battle a constant changing environment. It is important to notice that $88 \%$ of surveyed companies use strategic planning, which shows its importance.

On the other hand, Figure 2 shows that companies using strategic

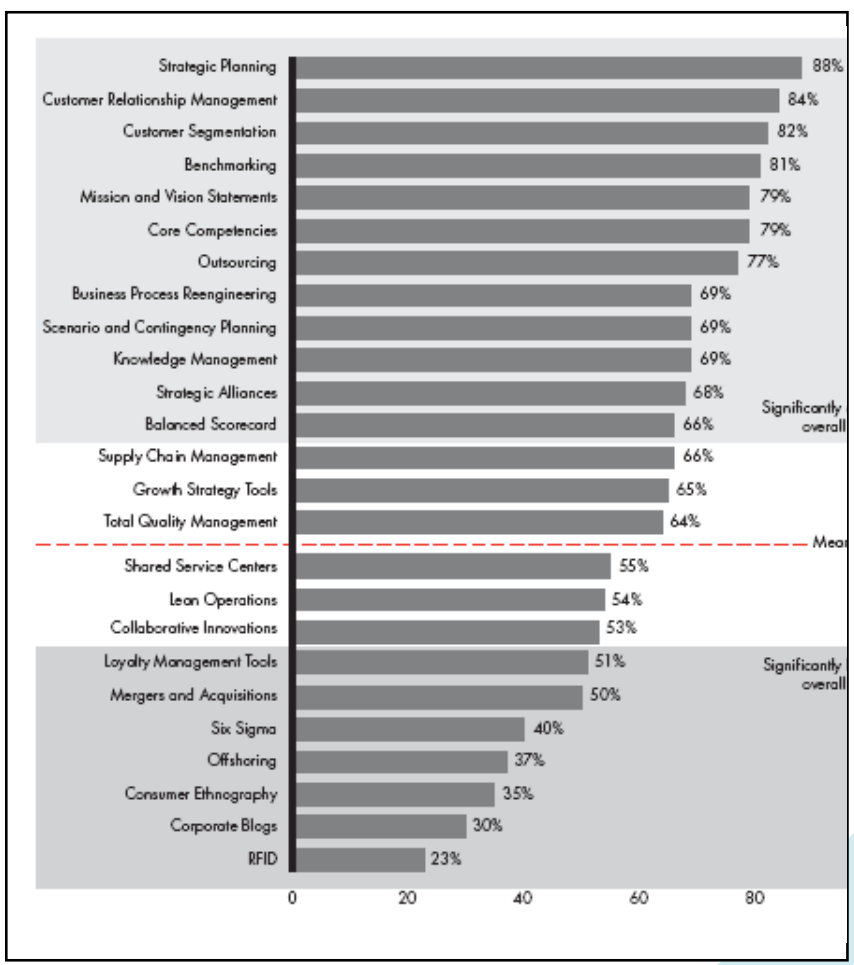


planning are very satisfied with this practice.

Therefore, the implementation of strategic planning in organizations is currently top priority worldwide, requiring great attention of organization managers. What is wanted is a great transformation in planning practices in order to improve the formulation of strategies in a way to satisfy all the needs of all interested parties.

In fact, a growing number of organizations in Brazil are adopting strategic planning, aiming to improve the orientation of various functional areas in order to improve the management of its processes, products and services, to contain its rising costs and provide better technical solutions and more focused on the clients. However, in many of these organizations, according to their own manager observations, the long-term orientation and their results are below expectations and clients are still dissatisfied.

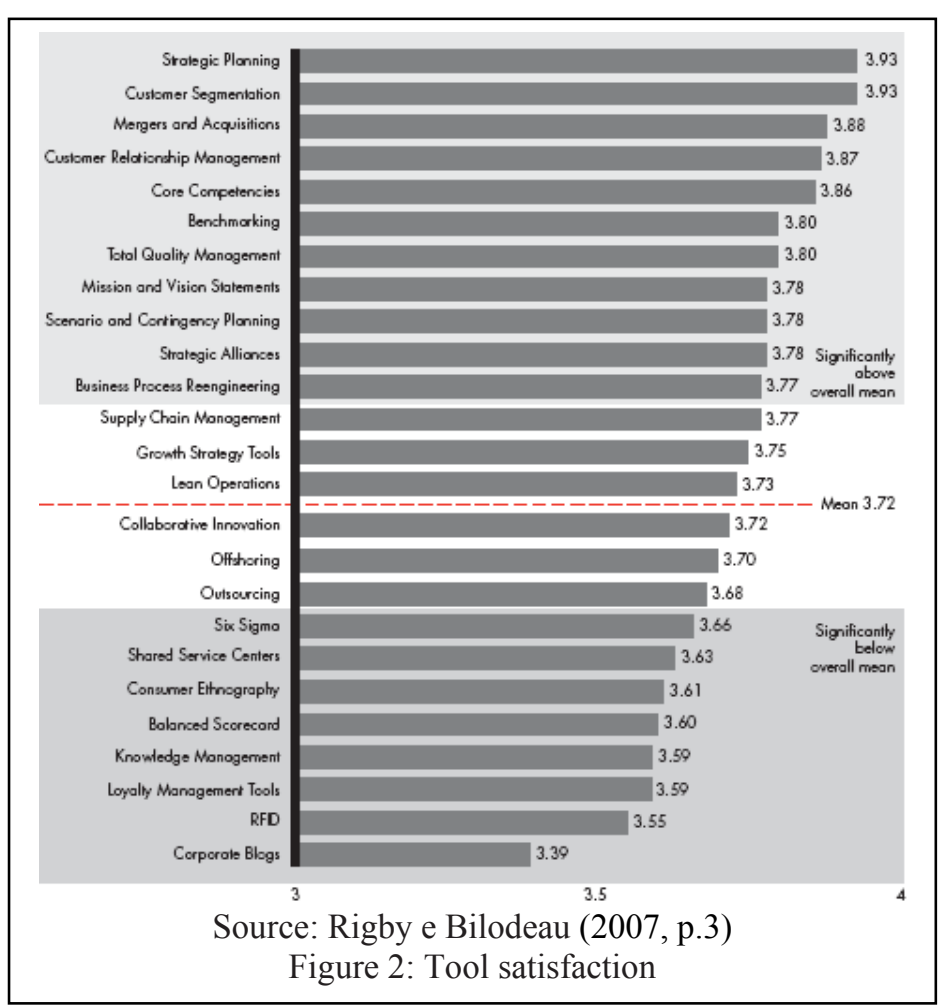

Actually, in a preliminary investigation conducted by the author in several organizations that consulting services were provided, it was observed that initiatives of strategic planning implementation have been fragmented and isolated, without providing the expected results (HEMORIO, 2000; EXÉRCITO BRASILEIRO, 2003; AGEVAP, 2008). It was also observed that there are in Brazil, several ways to implement the strategic planning, with few professionals who really have experience to implement a strategic planning model that is adapted to the specific contingencies to the industrial sector considered.

Thus, as can be seen on Figure 3, there is some urgency in developing and applying new implementation methodologies of strategic planning to improve organizational performance (RIGBY, BILODEAU, 2007, p. 5). The need to change 
toward higher levels of organizational performance appears as a fundamental requirement to be attended by those who want to gain in effectiveness and efficiency, for only this way, the organization will be able to achieve its strategic objectives set.

This article's goal is to present a methodology to implement effectively the strategic planning in an organization. It was based on a methodology developed by the author who has been improved over the last 15 years. It started from the principle that this methodology must be adaptable to the specific contingencies of the considered sector and needs to include a measuring system of its

\begin{tabular}{|c|c|c|c|c|c|}
\hline Top 10 most used tools & Global & North America & Europe & Asia-Pacific & Latin America \\
\hline Strategic Planning* & 1 & 1 & 1 & 2 & 1 \\
\hline Customer Relationship Management & 2 & 3 & 4 & 1 & 9 \\
\hline Customer Segmentation & 3 & 6 & $2(t)$ & 3 & $3(t)$ \\
\hline Benchmarking & 4 & 2 & $2(t)$ & $9(t)$ & 2 \\
\hline Core Competencies & $5(t)$ & 5 & $5(t)$ & 4 & 10 \\
\hline Mission and Vision Statements & $5(t)$ & 4 & 7 & $5(t)$ & 5 \\
\hline Outsourcing & 7 & 8 & $5(t)$ & $7(t)$ & $3(t)$ \\
\hline Business Process Reengineering & $8(t)$ & $10(t)$ & $10(t)$ & $5(t)$ & $14(t)$ \\
\hline Knowledge Management & $8(t)$ & 12 & $10(t)$ & $7(t)$ & $14(t)$ \\
\hline Scenario and Contingency Planning & $8(t)$ & 9 & 8 & 14 & 7 \\
\hline \multicolumn{6}{|c|}{$\begin{array}{l}\text { Figure 3: Strategic Planning is valued as the No. } 1 \text { tool everywhere in } \\
\text { the world except for the Asia-Pacific region. }\end{array}$} \\
\hline
\end{tabular}
performance that can help boosting the changes involved in the strategy implementation.

The purpose of this article is to present the results of applying the Methodology for Implementation of Strategic Planning. It was based on a methodology developed by one of the authors that has been improved over the last 15 years. It started from the principle that this methodology needs to be adaptable to specific contingencies and needs of the sector considered include a system for measuring performance that can help boost the changes involved in implementing the strategy.

The Methodology for Implementation of Strategic Planning - MISP was perfected that developed during doctoral research (NEVES, 2000) and also of the projects developed in several organizations in Brazil (AGEVAP, 2008).

It is necessary that, for the feasibility of planning, it created a structure adaptable to changing needs. For this, one must count with the presence of representatives from all areas of the organization with the goal of forming a broad view, through the participation of all sectors (BEER, EISENSTAT, SPECTOR, 1990). 
The MISP, that was developed by Neves S. (1996 and 2000), was adapted from the methodology "Design

School" from the School Management from Harvard University (ANSOFF, 1991) and taking into account some points and methods recommended by the Schools of Planning and Positioning (MINTZBERG, AHLSTRAND, LAMPEL, 1999), taking into account the factors that influence the management in organizations, the shortcomings of planning in Brazil and features of necessary chaining for the implementation, among other attributes. Moreover, to conduct a adequate planning, it was observed that it is necessary to

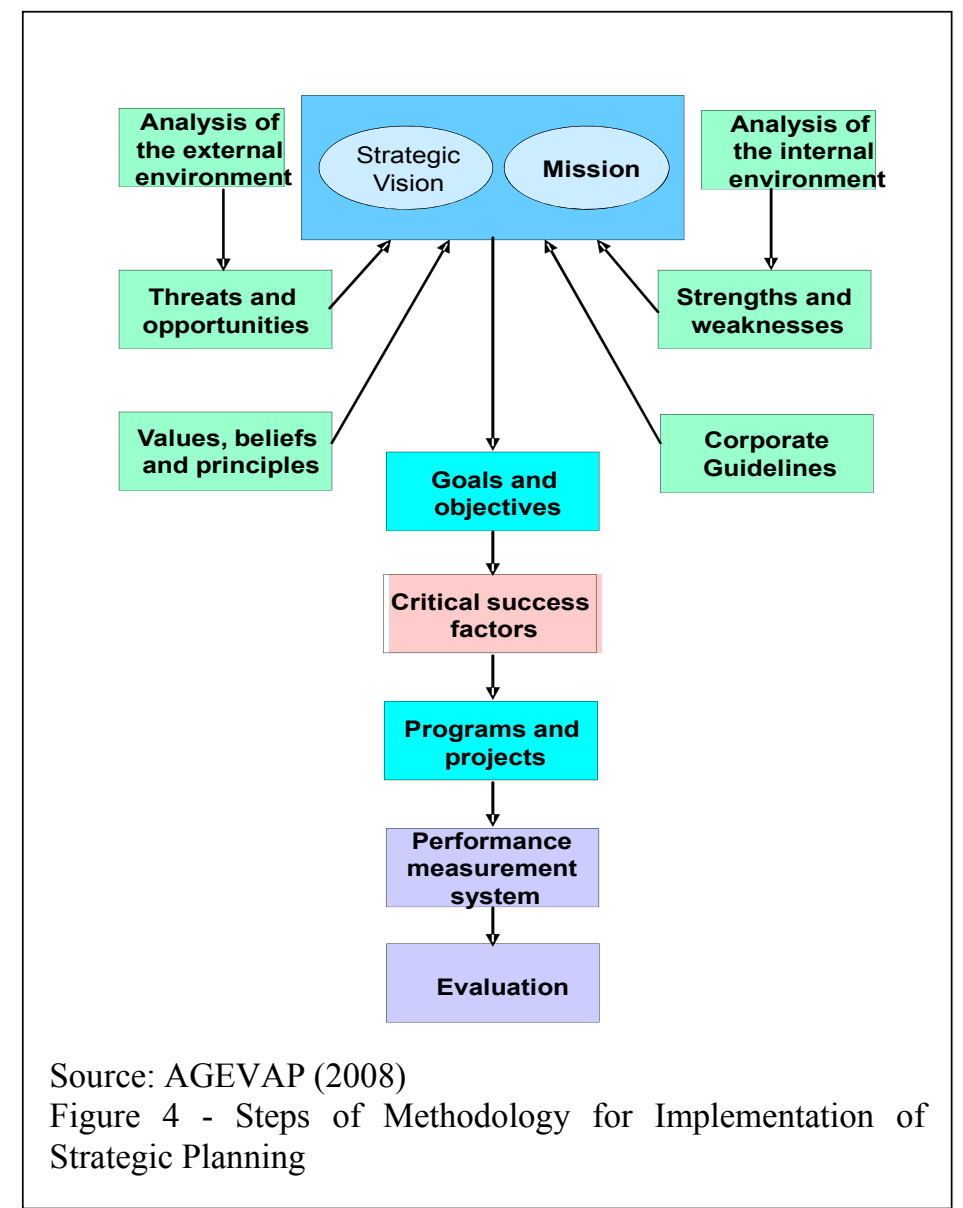
determine specific and measurable goals with deadlines realistic and achievable (ESTRADA, ALMEIDA, 2007).

The application of MISP follows the steps of the model in Figure 1, which can be adapted for each organization, depending on their characteristics.

The Methodology for Implementation of Strategic Planning - MISP was perfected from the one developed during research (NEVES S., 2000) and also from various organizations in Brazil (AGEVAP, 2008).

The viability of MISP can be seen, taken that it has already been applied in various public and private organizations, such as the General Comptroller of the District of Rio de Janeiro, Military Engineering Institute, HEMORIO, Central Army Hospital, Technological Center of the Federal University of Rio de Janeiro, Faculty of Technology, UERJ, Paraiba do Sul's Water Agency - AGEVAP, amongst others, with 
satisfactory results. These applications, summarized in Projects, are indicated at the end of the Methodology description.

Every organization develops its strategic planning as a way to prepare for the necessary changes within the modernization process. Thus, it establishes in witch strategic position it would like to be in a few years ahead (the amount of years depends on some aspects of the organization) and how to reach that future effectively. The acting environment of an organization is characterized by a quick advance in the environment areas, resources utilization, management and information.

A critical Mission analysis must be performed, of the Vision of Future, Politics, Strategies, Guidelines, Objectives and Goals, besides the actions related to the Plans of Action (KAPLAN, NORTON, 2008). In addition to this, within this new perspective, the organization must seek the equation of its budget, one way or the other; it shall influence the project programs to be established.

It is made necessary, for the planning operationalization, that a structure adaptable to the organizational needs is created. For that, the presence of representatives from all areas of the organization must be counted on, with the goal of forming a broad vision through the participation of all sectors (BEER, EISENSTAT, SPECTOR, 1990).

It important to distinguish that MISP has adopted analysis methods that consider the operational and administrative perspectives, meaning, as a view that highlights issues of the aspects related to the end-activity, and the effective use of administrative procedures to facilitate the activities of supporting processes.

This Strategic Planning Methodology is an action program outlined to be executed by the organization, being a way to prepare itself for to the new management demands that are being implemented throughout the world, and are also being aligned to the Excellence Standards (FNQ, 2009), considering that the end-activities and administrative have increased their complexity due to the wide range of knowledge and existing technologies that are increasingly available to all interested parties. This can be best seen on the current information access, plenty of them available on the Internet. 
The establishment of a strategy to an organization requires to be worked on the following aspects:

- The mission to be accomplished;

- The identification of objectives and organizational goals;

- The identification of what is fundamental to the accomplishment of the Mission and achieving the objectives (critical success factors);

- The structuring of the necessary actions to accomplish the goals and objectives.

The MISP, which was developed by Neves S. (1996 and 2000) was adapted from the "Design School" methodology from the Management School at Harvard University (ANSOFF, 1991) taking ito consideration some points and methods recommended by the Schools of Planning and Positioning (MINTZBERG, AHLSTRAND, LAMPEL, 1999), observing the factors that influence the management in Brazilian organizations, the deficiencies of planning in Brazil and the chain characteristics necessary to the implementation, amongst other attributes.

The application of MISP follows the model on Figure 4, which may be adapted in each organization, according to their characteristics, comprising the following steps:

- Analysis of External Environment,

- Analysis of Internal Environment,

- Identifying the values of the organization and Corporative Guidelines,

- Definition of the Strategic Vision and re-study of the Mission,

- Definition of Objectives and Targets,

- Definition of Critical Success Factors,

- Definition of Programs and Projects

- Development of the Performance Measurement System

- Evaluation.

From this point on, the steps that consist in the MISP are described, in order to facilitate understanding. 


\section{CRITICAL ANALYSIS OF THE DEVELOPMENT OF METHODOLOGY FOR IMPLEMENTATION OF STRATEGIC PLANNING}

\subsection{Step 1 - Analysis of External Environment}

In order to perform an appropriate strategic planning, a study use must be made to identify the impacts of external and internal environments on the organizational processes, also trying to verify the influences of the organization over these environments. Only after this analysis it will be possible to make a refinement of the Mission (in case it exists well-defined), verifying the adjustment of itself to the new realities of the environment where it acts.

The Analysis of the External Environment aims to verify the main Threats and Opportunities, seeking to identify the responsible factors for supporting or prejudicing the good performance of the organization (PORTER, 1991). Therefore, the organization monitors the "macro-environmental forces (political, demographic, economical, technological, legal, social and cultural) and the micro-environmental important actors (consumers, competitors, distribution channels, suppliers) that affect the ability to obtain profit (KOTLER, 1998, p 87).

Normally, questions are asked aiming to focus the attention of the work team to identifying the Threats and Opportunities (NEVES S., TAMMELA, 2010, p.32):

- Threats: "What external events will influence or could negatively influence the organization's performance in the future? What external events compromise the organization in the present?"

- Opportunities: "What external events will influence or could positively influence the organization's performance in the future? What external events help the organization in the present?"

The redaction of Threats and Opportunities is usually made through a listing of the ideas thought by the staff. The final redaction may be conducted by a facilitator, that through prioritizing techniques seek to evidence the Treats and Opportunities considered being most important and relevant to continue the work.

\subsection{Step 2 -Analysis of Internal Environment}

The analysis of the internal environment is a tool to check the organization's 
current state, being the first step to verify if the current strategy (in case it exists) is being effectively implemented, and if the current results are satisfactory. It also serves to identify critical areas, avoiding the loss of time caused by taking wrong decisions. Each organization, however, must determine the scope and depth of the valuation to be realized. To do so, questionnaires, interviews and even deeper specific techniques of verification may be used.

This Internal Environment Analysis seeks to achieve a diagnosis of the current organization situation, noting the variables that influence their performance, the fortresses and weaknesses of the internal environment (KRAJEWSKI, RITZMAN, 2004). This diagnosis process also provides information about the existence of feuds, resistance to changes, where the organizational system does not provide confidence to users of its services and if there are distortions in the choice of the organization priorities.

The Internal Environment Analysis aims to verify the main strong and weak spots of the organization, seeking to identify the internal factors responsible for favoring or prejudicing its good performance. In fact, through an exploratory process, it comes to a set of internal factors responsible for positively, or negatively, influencing the organization. Some questions may be asked that focus to concentrate work team's attention to identifying key Strengths and Weaknesses (NEVES S. and TAMMELA, 2010, p. 34):

- Strengths: What internally enables / encourages the organization to meet their activities? What internal characteristics the organization has that places it ahead of its competitors or similar organizations?"

- Weaknesses: What internally makes it difficult for the organization to meet their activities? What internal characteristic the organization shows that makes its acting difficult facing the changes in the sector where it acts?"

A survey must be made about the satisfaction levels of the workforce (employees and contractors), considering that this is an important information to be considered when selecting the most important initiatives to improve its performance. At this point, it is well suited to have an initial checking as to which indicators are 
necessary, how to achieve them and monitor them.

It is necessary to identify the current and desired performance levels, establishing a small diagnosis of the main organization processes in all levels. Based on this data, it will be possible to identify the main restrictions regarding the needs of the interested and to the performance of the processes considered to be critical to the organization. The evaluation's result in each sector will serve of basis for the improvement actions proposed.

At this point of the MISP, the top management can perform lectures and / or participate in meetings and lectures conducted by renowned consultants and executives from other organizations that are already implementing a strategic planning process, to show their commitment to changes, the importance strategic planning and use of new management tools to improve the organization management (HEMORIO, 2000; EXÉRCITO BRASILEIRO, 2003; SENAC-RIO, 2008). In fact, the personal commitment of managers, at all levels, will show that the use of good management practices is everyone's responsibility (BEER, EISENSTAT, SPECTOR, 1990).

\subsection{Step 3 - Identification of Organization Values and the Corporative Guidelines}

In order to start the strategic management process, it is necessary to define the new management practices that the organization identifies with, or will identify during the implantation. One of the most important functions of leadership, at all levels, is to introduce new Values, for the day-to-day, making this cultural basis appropriate to the new situation (KOTLER, 1998, p 92).

When a cultural change is wanted, it is essential that the Values that guide this change remain, for a long time, being repeated and reinforced until they become irreversible. This only occurs when they become part of the organization's new culture, regardless of changes in top management. For this, it is necessary to answer the following questions (NEVES S., TAMMELA, 2010, p. 34):

- "What is being valued by the management of the organization?"

- "What will be valued by the management in the future, so that members 
of the organization may understand what is really important for an effective change development?"

Another important issue is the verification of the main Corporative Guidelines to be implemented by the organization. To do so, planning documents, guidelines, resolutions and / or deliberations related to the organization of the corporation or other guidelines which top management judges to be appropriate, could be analyzed. This way, the following questions must be answered (NEVES and S. TAMMELA, 2010, p. 35):

- "What are the main guidelines of the corporation, its needs, determinations and priorities?"

- "What explanations were given by the higher hierarchic level on the actual guidelines of the corporation in order to clarify questions regarding the purposes and competences of the organization?"

\subsection{Step 4 - Setting the Strategic Vision and re-study of the Mission}

a) Definition of the Strategic Vision

In the preparation of Strategic Vision, the organization takes into consideration that it portraits a possible and desired situation in a long-term horizon. Strategic Vision is an ideal condition, a desire, an achievable dream, a challenge, what the organization wants to be in the future (AGEVAP, 2008). This vision is conceived from the External and Internal environments Analysis, and consistent with the guidance provided by the controller of the organization, if any.

The Strategic Vision should be developed in a way to represent an innovative goal, translating the feeling of continuous improvement, for the confidence in a better future is the common tonic in the expressions of a vision and a fact to the organization members that has already been detected in the internal environment analysis. Within this spirit, the Strategic Vision should not just be informed, but shared by all components of the organization, for it will be a propelling factor to the change. In general, it is what will make the leadership initiate actions. Thus, the following questions must be answered (NEVES S., TAMMELA, 2010, p. 37):

- "What the organization wants to be in the future?" 
- "How does the organization want to be recognized as in the future?"

Although at first glance the Strategic Vision is a highly ambitious goal for the organization, it suits well to warn that it is much better to set more difficult goals than easy, because these do not motivate people to pursue them. On the other hand, almost impossible goals should not be established, because these, in turn, discourage people for considering they never will reach them (NEVES S., 1996).

\section{b) Definition of Mission}

The Institutional Mission is the reason of being for the organization. The detailing of the organization's mission is very important, but it is necessary to have clarity and consensus regarding what is wanted to achieve, and the priorities of what is offered. Having this done, the mission of the Agency may be detailed in a succinct and objective way. The definition of the organization's mission takes into consideration the analysis of external and internal environments, carried out by the development team of strategic planning.

Usually after several debates and considerations by team members, a Mission consolidation for the organization is achieved, so as to constitute one of the basis of strategic planning development.

\subsection{Step 5 - Definition of Goals and Targets}

Goals are targets to be met in a given period. Strategic Objectives set by the working group are the basis for the organization to work with clear measures that guide managers. The Organization's Strategic Objectives are established in order to achieve the Strategic Vision and the accomplishment of the Mission.

For the organization's management to be aligned with corporative guidelines, the goals determined by the corporation should not be forgotten, for they provide the desired directing.

In order to set goals and objectives following the following questions must be answered (NEVES S., TAMMELA, 2010, p. 38):

- Objectives: "What is the future state of the organization or results to be obtained or maintained, to ensure that the mission is fulfilled and the Strategic Vision is achieved by the predicted deadline?" 
- Goals: "What are the specific goals, measurable, and which attainment is desired at an interval of determined time?"

It is important, then, that the Objectives and or Goals of the organization are clearly established, in order to align to what the top management desires and the plans to be deployed from these goals.

\subsection{Step 6 - Definition of Critical Success Factors}

For the strategic vision and goals were transformed into clear programs and projects, strategic planning predicts the definition of Critical Success Factors (CSF), meaning, the decisive attributes to the successful implantation of the strategy in the organization.

The CSF, as well as the key indicators of performance, has as goal aligning to the skills, capabilities, processes, learning and culture with the greatest goals of the organization and development of detailed measures to evaluate its effectiveness.

To define your CSFs, the organization must answer the following questions (NEVES S., TAMMELA, 2010, p. 39):

- "What are the decisive attributes for the success of the organization in the fulfillment of its mission and achieving its strategic vision?"

- "What will make the organization be well-succeeded on its Mission and achieving its Strategic Vision?"

It is worth emphasizing that it will be necessary to define the vital few Critical Success Factors that are related to each one of the main strategic objectives. To set these CSF, from Strengths and Improvement Opportunities, Threats and Opportunities, Mission and Strategic Vision, in addition to skills and resource necessities can be used as sources of advice.

\subsection{Step 7 - Definition of Programs and Projects}

From the elaboration of Strategic Objectives and its Critical Success Factors, the team that assists in developing the strategic planning seeks to identify the Programs, Projects and the necessary actions to the achievement of the goals set, meaning, it establishes what should be done so that the organization can achieve the Strategic Vision. 
To facilitate the elaboration of a strategic planning it will be required that staff of the organization seeks to unfold the strategy, identifying for each "what" will be held, the "who" will be responsible for its implementation and "how" will be made for each action. For this, the organization's strategy and its deployment could be presented as a matrix.

This strategic planning methodology predicts the existence of an alignment of the strategies of the organization (Corporative) with the strategies of each one of its units (Mission, Future Vision, Politics, Strategies, Guidelines, Objectives and Goals, in addition to action plans).

On this step, it is predicted the development of implementation planning medium-term activities related to implementation of strategic planning in order to establish the direction to be followed by the organization in coming years.

For an effective dissemination of the activities developed in strategic planning to be done, it is necessary to structure the necessary mechanisms for communication: newspaper, internal newsletter, bulletin boards, magazines etc., in order to clarify to employees about the various phases of the strategy and how they can assist in its development (BEER, EISENSTAT, SPECTOR, 1990).

Finally, on this step, the various implementation teams in each sector of the organization will be structured.

\subsection{Step 8 - Development of Performance Measurement System}

Besides the necessity of having a strategic planning as a guideline of the organization, with the establishment of the Future Vision, Mission and Critical Success Factors, the methodology requires the proper application of a measurement system, which requires specific knowledge matters related to the management of projects with multidisciplinary teams.

The measurement system should include performance measures and its indicators. Firstly, an analysis of "what to measure" should be performed. After, the indicators related to the different perspectives of performance that were considered important by top management of the organization, are identified. This definition of the measurement system is important to align, inclusive the performance indicators of 
project implementation with measures of overall performance of the organization (KAPLAN, NORTON, 2008).

The strong commitment of the organization's senior managers is necessary to the implementation of the measurement system, for it will be a decisive inducer of the new focus culture on results. It is noteworthy that some indicators may already exist and are currently being used by the organization, however without an effective application of that information, at all levels of decision making, for decision taking.

In order to implement the Measurement System, these base indicators may be used and, with the help team with representatives of various sectors and specialists, establish balanced strategic indicators, in a "top-down" way, meaning, taken the needs of Senior Management, until its unfolding in each sector of the organization.

An effective implementation of the measurement system also involves it self's communication throughout the organization, its strategic level's unfolding to the various sectors, the details in indicators as to measurement frequency formulas, segmentation and visualization, linking compensation to results, the establishment and incorporation of a monitoring and controlling process, enabling continuous improvement of the indicators, along with analysis and review of actions, objectives and strategic goals (AGEVAP, 2009, p. 12).

As a suggestion, the implementation of the Performance Measurement System of the Organization can include the following steps (AGEVAP, 2009, p. 1218):

- Mapping of the Strategic Orientation

- Definition of Perspectives

- Definition of Strategic Objectives

- Creation of the Strategic Map

- Definition of Strategic Indicators (Assembly of the Board Panel)

- Detailing Strategic Indicators

- Definition of Display Form of the Organization 's Strategic Indicators

- Definition of Software to be used to manage the Organization's Performance Measurement System Organization 


\subsection{Step 9 - Evaluation}

This step aims to evaluate the results of the strategic planning implantation in the organization, in a way to provide feedback of the actions that were implemented. For this, the Performance Measurement System (Step 8) has a key role. It should be noted that there must be a change in the very evaluating process of the organization, which does not systematically use the performance indicators.

Each sector will have to establish its respective indicators with the corresponding graphs and tables. Modern software could be adopted to facilitate the strategy management, through projects, which include the key performance indicators, allowing managers to have better conditions to take decisions over a determined subject or point.

A schedule of coordination meetings should be structured with the Director of the organization, with the sectors and members of the structure "ad hoc" (BEER, EISENSTAT, SPECTOR, 1990), developed specifically to follow foreseen activities in the strategic planning. Also, Kaplan and Norton (2008) suggest the adoption of a Strategic Management Unit to run the processes with multiple system interfaces of strategy execution, in order to work as an architect, integrator and owner of the strategy control and planning process.

\section{CONCLUSIONS}

Changes in the economy have been accelerated by the globalization of markets, the technological changes and deregulation. All this strongly altered the competition.

The past success does not guarantee the future of organizations, for the economy, technology, people and power of nations are in full change. Therefore, strategic planning is pointed as the main tool to changes development in an organization.

There are some aspects that are critical to the strategic planning development, such as sensitiveness and involvement of all people, the definition of critical areas and priorities linked to the achievement of objectives and goals, the necessity of an 
"Ad hoc" structure for monitoring, the clear definition of responsibilities and performance indicators.

It should be noted that the strategic planning process should be understood by all and be participative, so there is a real commitment of all. For this, a clearly presented methodology, structured and linked with linked steps can serve this purpose.

Therefore, a balanced measurement system is a support methodology to follow and monitor the evolution of the organization decisions, focusing on strategic indicators. In general, the measurement system provides the organization a wide business vision, current and future, trying to translate the mission, the vision and strategies of the different organization goals and objectives, according to the performance perspective.

The strategic planning methodology here presented has a wide range of acting areas, which can be applied in large corporations as well as in micro and small enterprises. There is no distinction in whether the company is public, private, NGOs, government, or if it is used on people. However, different market situations, product strategies and competitive environments require customized systems (scorecards) that fit their mission, strategy, technology and culture.

Therefore, it is noteworthy that every organization is unique, as is its own way of implementing its strategic plan. So the Methodology for Implementation of Strategic Planning - MISP should also be adjusted to each organization, for it was developed to be implemented in the context of changes of organizations, and might be, however, perfected throughout its existence.

\section{References}

AGEVAP - Associação Pró Gestão das Águas da Bacia Hidrográfica do Rio Paraíba do Sul. (2008) Delineamento Estratégico 2008-2011. Resende/RJ.

AGEVAP - Associação Pró Gestão das Águas da Bacia Hidrográfica do Rio Paraíba do Sul. (2009) Sistema de Avaliação de Resultados. Resende/RJ. 
AMERICANO, A. C. (2009) Indústria Demite pelo Quarto Mês Consecutivo em Janeiro. Artigo publicado na Gazeta Mercantil em 13/03/2009. Disponível em www.iedi.org.br. Acesso em 25 de março de 2009.

ANSOFF, H. I. (1991) Critique of Henry Mintzberg's "The Design School: Reconsidering the basic Premises of Strategic Management". Strategic Management Journal, v. 12, p. 449-461.

LIMA, S. (2009) Indústria tem pior resultado desde Collor. Artigo publicado na Folha de São Paulo em 07/03/2009. Disponível em www.iedi.org.br. Acesso em 12 de março de 2009.

BEER, M.; EISENSTAT, R. A.; SPECTOR, B. (1990) Why Change Programs Don't Produce Change. Harvard Business Review, nov/dec, p. 158-166.

EXÉRCITO BRASILEIRO. (2003) Programa de Excelência Gerencia do Exército Brasileiro - PEG-EB. Brasília.

FEIJÓ, C. A.; CARVALHO, P. G. M. (2008) Evolução da produtividade da indústria em 2007. Estudo do Instituto de Estudos para o Desenvolvimento Industrial. São Paulo, maio de 2008.

FUNDAÇÃO NACIONAL DA QUALIDADE - FNQ. (2009) Critérios de Excelência. São Paulo.

HEMORIO. (2000) Instituto Estadual de Hematologia Arthur de Siqueira Cavalcanti. Estratégia de Implantação do Programa de Qualidade do HEMORIO. Rio de Janeiro.

INSTITUTO DE ESTUDOS PARA O DESENVOLVIMENTO INDUSTRIAL - IEDI. (2007) Indústria: Os dois pólos. Disponível em www.iedi.org.br. Acesso em 8 de junho de 2007.

KAPLAN, R. S.; NORTON, D. P. (1997) Balanced Scorecard: a estratégia em ação. Rio de Janeiro: Campus.

KAPLAN, R. S.; NORTON, D. P. (2008) A Execução Premium. Rio de Janeiro: Editora Elsevier. 
KOTLER, P. (1998) Administração de Marketing: análise, implementação e controle. São Paulo: Atlas, $5^{\mathrm{a}}$ edição, $8^{\mathrm{a}}$ Tiragem.

LIKER, J. K. (2004) The Toyota Way: 14 Management Principles from the World's Greatest Manufacturer. New York. McGraw-Hill.

LIMA, S. (2009) Indústria tem pior resultado desde Collor. Artigo publicado na Folha de São Paulo em 07/03/2009. Disponível em www.iedi.org.br. Acesso em 12 de março de 2009.

MINTZBERG, H.; AHLSTRAND, B.; LAMPEL, J. (1999) Safári de Estratégia: um roteiro pela selva do planejamento. Porto Alegre: Bookman, 1999.

NEVES S., JOÃO A. (1996) A Importância do planejamento na implantação da Qualidade Total. XVI Encontro Nacional de Engenharia de Produção - ENEGEP. Piracicaba.

NEVES S., JOÃO A. (2000) Estratégias de melhoria da qualidade orientadas para o cliente na saúde no Brasil: um modelo para auxiliar sua implementação em hospitais. Tese de Doutorado, Departamento de Engenharia Industrial, Pontifícia Universidade Católica do Rio de Janeiro. Rio de Janeiro.

NEVES S.; JOÃO A.; TAMMELA, I. (2010) Agência Nacional de Vigilância Sanitária - Planejamento Estratégico Organizacional. Apostila do Curso. Programa de Cooperação Universidade Federal Fluminense e ANVISA. Brasília.

PORTER, M. E. (1991) Estratégia Competitiva: técnicas para análise de indústrias e da concorrência. Rio de Janeiro: Campus.

RIGBY, D.; BILODEAU, B. (2008) Management Tools and Trends 2007. Bain Company. Disponível em www.bain.com. Acesso em 18 de setembro de 2008.

SERVIÇO NACIONAL DO COMÉRIO - RIO DE JANEIRO - SENAC-RIO. (2008) Proposta do Programa Excelência SENAC 2010 - Modelo de Implementação. Rio de Janeiro.

TRIST, E. (1976) Some Concepts of Planning. National Seminar on Long-range Planning. University of Western Australia. 